\title{
Trabajo y ocio en las vidas de los profesionales creativos
}

\author{
José Ángel Bergua \\ Universidad de Zaragoza \\ jabergua@unizar.es
}

\section{Resumen}

El artículo expone los resultados de parte de una investigación sobre las clases creativas en España utilizando la técnica de Historias de vida. En concreto presta atención al trabajo y al ocio, tanto por separado como las relaciones que tienen pues en los trabajos realizados por Richard Florida este asunto es fundamental. Por lo que respecta a la relación de ambas actividades, los informantes se ubican en todas las combinaciones (separación, bibridación y dominación de una u otra actividad). En relación al ocio observamos que es variado pero permite distinguir un perfil bumanista de otro profesional. Y en cuanto al trabajo, las actitudes colaborativas tienen más peso que las individualistas

Palabras clave: juego, individualismo, colaboración, modernidad.

\begin{abstract}
The article presents the results of an investigation into the creative classes in Spain using the technique of life stories. In particular focuses work and leisure very important for the Richard Florida's works. We observed that our informants make all posible combinations between them (separation, bybridization and domination of one or other activity). On the other hand, we discovered that, in leisure terms, itis posible to distinguish the humanist informants from the profesional ones. Finally, we also saw that, in the work área, the collaborative attitudes were more important that the individualistic ones
\end{abstract}

Key words: play, individualism, colaboration, modernity. 


\section{Introducción}

En los últimos tiempos la creatividad se ha convertido en un importante objeto de reflexión, análisis y controversia. Se habla de ella desde un punto de vista económico (Hawkins, 2005), sociológico (Joas, 1996, 2012) o psicológico (De Bono, 2006; Csíkszentmihályi, 1996) y ha entrado en los debates sobre las clases sociales, la ciudad, la industria y la educación entre otros asuntos. Sin embargo, desde que Richard Florida (2010) publicó The Rise of Creative Class el año 2002, la creatividad ha elevado su popularidad en el ámbito de las ciencias sociales $y$ ha estimulado infinidad de investigaciones.

Una de las originalidades de las investigaciones de Florida es haber construido un indicador de la creatividad que combina tres variables: tecnología, talento y tolerancia. De ellas la última es la que añade más originalidad y un perfil más sociológico a la medida. Sin embargo, según nuestras investigaciones ${ }^{1}$, tanto en Europa como en España la Tolerancia y sus tres subíndices (proporción de homosexuales, bohemios y extranjeros - caso de España- y tolerancia, autoexpresión y racionalización-secularización -caso de Europa-) correlacionan muy mal con el indicador general (Báez, Bergua y Pac, 2014). Para solucionarlo nos propusimos prestar atención no exactamente a la tolerancia sino más bien a una noción previa, la heterogeneidad y diversidad social ${ }^{2}$. Para ver cuánto de estos componentes había en los profesionales creativos e igualmente para averiguar cómo se construye socialmente esta clase de sujeto decidimos utilizar como técnica de investigación las historias de vida.

Apostamos por esta técnica debido que su objetivo general se adapta a nuestras necesidad ${ }^{3}$, dado que trata de obtener información a partir de personajes ejemplares o representativos para ver cómo han interiorizado ciertos acontecimientos, experiencias o procesos en el que se desenvuelven hasta hacerlos formar parte de su personalidad ${ }^{4}$. Dicho de otro modo, los datos biográficos producidos interesan por el hecho de mostrar la influencia del contexto social en un indivi-

1 El presente artículo es resultado de la investigación "Clases creativas en España: composición, formación y creatividad”, realizada entre 2011 y 2013, financiada por el Ministerio de Economía y Ciencia (ref. CSO201017139).

2 Más lejos llega Freud (Arieti, 1976: 22-26) al sugerir que la creatividad, como la neurosis, se origina en conflictos. En su opinión, el creativo es un tipo sexualmente frustrado que sublima dicho conflicto. Como se verá, no hay datos en las vidas de nuestros informantes que nos obliguen a pensar la construcción del creativo en estos términos.

3 Acerca de esta técnica véase De Miguel (1996), Sarabia (1985) y Pujadas (1992).

4 Hay una tendencia en las historias de vida, lamentada por De Miguel (1996), que lleva a hacerse sobre personajes exóticos, pintorescos o marginales y, en cambio, se utilice menos para investigar a la anodina clase media, cuando por su numero e influencia en la sociedad debería merecer ese protagonismo. Afortunadamente, cada vez más investigaciones huyen de esa tendencia. Creemos que es el caso también de ésta. 
duo. Esto implica que es necesario saber pasar en los análisis de los datos personales obtenidos a lo colectivo. Esa es la diferencia entre las historias de vida y las biografías.

El diseño de la muestra de perfiles a partir de la cuál elegimos los personajes ${ }^{5}$ lo realizamos en varias etapas y teniendo en cuenta distintas variables con sus correspondientes categorías. En primer lugar, según nuestros datos, en 2010 había 4.133.600 personas trabajando en 18 tipos de ocupaciones creativas, distribuidas según lo indica el cuadro I. Atendiendo al peso de cada ocupación y las afinidades que mostraban entre si decidimos reducir el conjunto a 9: un responsable de dirección y organización de empresas, un profesional de la publicidad o marketing, un profesor e investigador de las ciencias duras y del ámbito público, un diseñador, un médico o veterinario, un profesional del derecho, un ingeniero y un Arquitecto o urbanista.

\section{Cuadro I. Clases creativas en 2010}

\begin{tabular}{|c|c|c|c|}
\hline & 2010TII & \multicolumn{2}{|c|}{ 2010TII HISTORIAS DE VIDA PROPORCIONALES } \\
\hline 22 Profesiones asociadas a titulaciones de 20 y 3 er ciclo universitario en la enseñanza & 449,9 & 2,4 & 0,968609865 \\
\hline 28 Profesiones asociadas a una titulación de 1er ciclo universitario en la enseñanza & 444,4 & 2,4 & 0,968609865 \\
\hline 11 Dirección de empresas & 426,4 & 2,3 & 0,928251121 \\
\hline 20 En ciencias fisicas, químicas, matemáticas e ingeniería & 303 & 1,6 & 0,64573991 \\
\hline 21 En ciencias naturales y sanidad & 278,5 & 1,5 & 0,605381166 \\
\hline 14 Gerencia de otras empresas & 276,2 & 1,5 & 0,605381166 \\
\hline 24 Profesionales en organización de empresas, ciencias sociales y humanas & 257,9 & 1,4 & 0,565022422 \\
\hline 15 Gerencia de empresas de comercio sin asalariados & 243 & 1,3 & 0,524663677 \\
\hline 27 En ciencias naturales y sanidad y asimilados, excepto ópticos y fisioterapeutas & 241,5 & 1,3 & 0,524663677 \\
\hline 26 En ciencias físicas, químicas, matemáticas e ingeniería y asimilados & 216,1 & 1,2 & 0,484304933 \\
\hline 12 Gerencia de empresas de comercio & 168,1 & 0,9 & 0,3632287 \\
\hline 23 Profesionales del derecho & 156 & 0,8 & 0,322869955 \\
\hline 29 Otras & 153,9 & 0,8 & 0,322869955 \\
\hline 25 Escritores, artistas y otras & 148,1 & 0,8 & 0,322869955 \\
\hline 13 Gerencia de empresas de hostelería & 125,5 & 0,7 & 0,282511211 \\
\hline 16 Gerencia de empresas de hostelería sin asalariados & 110,8 & 0,6 & 0,242152466 \\
\hline 17 Gerencia de otras empresas sin asalariados & 104,9 & 0,6 & 0,242152466 \\
\hline \multirow[t]{2}{*}{10 Poder ejecutivo y legislativo de la administración pública, dirección de organizaciones } & 29,4 & 0,2 & 0,080717489 \\
\hline & 4133,6 & 22,3 & 9 \\
\hline
\end{tabular}

(Fuente: INE. Elaboración propia)

En segundo lugar, tuvimos en cuenta el ranking de creatividad por CCAA pues permite distinguir cuatro grupos (Báez, Bergua y Pac, 2014). En primer lugar, aquellas Comunidades que han obtenido más del 64 puntos sobre 100: Madrid, Cataluña, Navarra y el País Vasco. En segundo lugar, están las que podríamos calificar como de resultados aceptables, con alrededor de 40 ó 50 puntos: Aragón, Comunidad Valenciana, La Rioja, Baleares, Canarias, Asturias, Castilla

5 Para investigar universos relacionados con el sentido, aunque resida en el contexto y no en los discursos e imaginarios, como es el caso de las historias de vida, se utilizan muestras estructurales (tienen que ver con el conjunto de posiciones y relaciones sociales decididas como pertinentes) construidas no aleatoriamente sino intencionalmente (es decir, saturando todas las contradicciones ideológicas y materiales concernidas por la investigación) (De Lucas, 1995: 109). 
y León y Murcia. En tercer lugar, las Comunidades con malos resultados, alrededor del 35 ó 36 puntos: Andalucía, Galicia y Cantabria. Por último, las de pésimos resultados, por debajo de los 30: Extremadura y Castilla-La Mancha. Esta variable y sus correspondientes categorías decidimos representarla con 5 personajes provenientes de las comunidades punteras (Cataluña, País Vasco y Madrid), 2 de una de las comunidades que peor puntúa (Galicia) y otros 2 informantes de una comunidad que está en la posición media (Aragón)

Además de la ocupación y del índice de creatividad por Comunidades Autónomas decidimos utilizar como criterios muestrales las variables edad (distinguiendo dos categorías: menor ó igual a 40 años y mayores de 40 años), y el genero (varón/mujer). A estas 4 variables principales y 16 categorías añadimos 3 variables auxiliares con sus correspondientes 8 categorías (estado civil - soltero/a, casado/a, divorciado/a - , si tienen o no hijos/as y actividad —empresario/a y trabajador/a autónomo/a o por cuenta ajena-).

Combinando todas las variables y categorías definimos la lista de perfiles que aparece a continuación. En ella hemos subrayado las características adicionales de los personajes finalmente seleccionados.

- Perfil 1: responsable de dirección y organización de empresas (medianas o grandes), varón, mayor de 40 años, Aragón (soltero y sin hijos) (trabajador por cuenta ajena, alto cargo)

- Perfil 2: profesional de la publicidad o marketing, mujer, menor de 40 años, Madrid (casada, 1 hijo pequeño que ya va a la guardería) (autóno$\mathrm{ma})$

- Perfil 3: Profesor e investigador de las ciencias duras y del ámbito público (Universidad, Institutos de Investigación, CSIC, etc.), varón, mayor de 40 años, Galicia (casado y con 2 hijas) (trabajador funcionario por cuenta ajena)

- Perfil 4: Artista (escritora), mujer, menor de 40 años, Madrid (con pareja de hecho, sin hijos) (trabajadora por cuenta ajena)

- Perfil 5: Escritores y artistas (diseñador), varón, mayor de 40 años (54), Aragón (casado y con 2 hijos) (autónomo)

- Perfil 6: Médicos y veterinarios, mujer, menor de 40 años, País Vasco (casada, sin hijos) (residente en un hospital, trabajadora por cuenta ajena)

- Perfil 7: Derecho (abogado, juez, etc.) varón, mayor de 40 años, Galicia (soltero sin hijos) (autónomo) 
- Perfil 8: Ingeniero, mujer, menor de 40 años, País Vasco (separada de su pareja de hecho y estrenando una nueva relación en México, sin hijos) (trabajadora por cuenta ajena, alto cargo)

- Perfil 9: Arquitecto o urbanista, mujer, mayor de 40 años, Cataluña (divorciada hace 3 años con 2 hijos de 12 y 11 años y una hija de 7) (trabajadora por cuenta ajena en el ayuntamiento de una ciudad media catalana)

\section{Trabajo y tiempo libre}

Dice Florida (2002: 14) en relación al modo como los miembros de la clase creativa compaginan su tiempo de trabajo y el de ocio, que es singular, pues parece que juegan cuando están trabajando y no se desconectan de sus ocupaciones en su tiempo libre. Esto es - añade - porque "la creatividad no puede ser enchufada y desenchufada en tiempos predeterminados, pues ella misma es una mezcla de trabajo y juego" ${ }^{\text {. }}$.

Por lo tanto, a pesar de la institucionalización de dos tiempos claramente diferenciados, las clases creativas activan sobre ese fondo una mezcla anárquica. Pero esta conducta es disidente respecto al orden instituido en la Modernidad, no sólo porque cuestiona la distinción, sino porque revaloriza el ocio y lo hace competir de igual a igual con el trabajo. En efecto, la obligación de trabajar que, según Weber (1981), fue introducida en las almas por el protestantismo y resultó tan útil al capitalismo, la consideración del trabajo como una de las principales cualidades humanas según el marxismo ${ }^{7}$ e incluso el argumento del carácter terapéutico atribuido hoy al trabajo, pero que ya encontramos defendido en el socialismo utópico de Fourier, demuestran que la Modernidad se autoinstituyó colocando en el centro de la existencia colectiva al trabajo ${ }^{8}$.

El juego de posibilidades que abre el mayor o menor peso del trabajo y del ocio en las combinaciones jerárquicas y anárquicas de ambos tipos de tiempo, colocan el diagnóstico de Florida en su justo lugar. Como combinación anárquica que es, no sólo se diferencia de esa modernidad fuerte, que puso por encima de todo el trabajo, sino también de su espejo simétrico e inverso, la postmodernidad fuerte, en la que el ocio, y más específicamente el juego, es visto como lo más

\footnotetext{
6 Sobre esta abolición de la distinción también ha llamado la atención Fumagalli (2010:268) y entiende que es un paso más en la explotación directa del bios que la "bioeconomía contemporánea lleva a cabo.

7 No olvidamos que bastante marxismo se ha distanciado de la posición central adjudicada al trabajo. Es el caso de Lafargue (1980). Por otro lado, tampoco habría que olvidar quienes, como Jünger (1993), observan en el trabajo una gran fuerza capaz de transformar la sociedad, pero de un modo distinto a como lo consideran el capitalismo y los marxismos, desde este punto de vista dos variantes de lo mismo.

8 Los lamentos por la pérdida de ese pilar fundacional de la modernidad y la caída en el hedonismo están encabezados por Bell (1987).
} 
importante. Así habría ocurrido en el mundo antiguo si observamos que otium es el término primero y principal sobre el que se construye el neg-otium. Del mismo modo, Huizinga (1972) y Caillois (1967) nos recuerdan que la cultura nace del juego espontáneo, Winnicott (1993) descubre que el infans se incorpora al mundo también de un modo lúdico y Bataille (1987) ve en esa actividad una exuberancia y voluptuosidad que se opone a la racionalidad, mesura e instrumentalidad del trabajo de las sociedades complejas ${ }^{9}$. En todos esos casos, el lugar central de la actividad social lo ocupa el homo ludens, no el homo laborans. Y las esferas sociales en las que mejor se desenvuelve, como el arte o la fiesta, están escasa o nada emparentadas con el capitalismo. Pues bien, la clase creativa de Florida tiene que ver con una postmodernidad débil en la que, si bien el ocio y el divertimento ocupan un lugar central, no se llega al extremo de suponer que dominan absolutamente al trabajo ${ }^{10}$. Más bien le influyen y contaminan para terminar mezclando con él.

Finalmente, la posición analítica de Florida difiere también de la modernidad débil, que representa cierto capitalismo de consumo donde el trabajo no pierde importancia y extiende su habitus ${ }^{11}$ al ámbito del ocio o del tiempo libre. Así ocurriría con las actitudes esforzadas y el entrenamiento o destreza que exigen algunos disfrutes. No sólo es el caso de las actividades deportivas, pues también ese capitalismo ficción del que nos habla Verdú (2003), caracterizado por producir y vender experiencias, exige una actitud más activa y comprometida que el capitalismo de consumo. Es el caso, por ejemplo, del turismo (McDanell, 2003). Igualmente cabrían dentro de esta modernidad débil las actividades de ocio que son continuación de la actividad profesional ${ }^{12}$.En definitiva, estamos ante un ocio que, por diferentes vías, aunque resulte paradójico, incorpora un importante componente ascético ${ }^{13}$.

9 Tampoco habría que olvidar a Jefferson: "la buena aptitud ciudadana que se da en el juego se pierde en el trabajo" (Sennett, 2009: 236). Más lejos apunta Fink (1966), cuando ve en el juego la intervención de una omnipotencia creadora de carácter divino que invade lo humano. En la misma dirección apuntan los análisis de Berger (1999) sobre la risa.

10 Creemos que esa es también la posición de Dumazidier (1988) cuando analizó la que llamó "revolución del tiempo libre".

11 Acerca del habitus véase, por ejemplo, Bourdieu (1997).

12 Desde otro punto de vista, cabría incluir aquí los intentos de las ciudades para atraer a los creativos a partir de actividades de ocio creativo, lo que beneficiaría a unas y otros, tal como sugiere Florida (2009: 128). Sin embargo, Houston, Finday, Harrison y Mason (2008) opinan que es mejor atraerlos con buenas oprtunidades económicas. Pohl (2008), por su parte, asegura que la presencia de la clase creativa, aunque juegue un importante rol en la estructura socioespacial al incrementar la diversidad, no mejora el desarrollo.

13 Banks (2009: 668-681) ha subrayado otra paradoja cercana a ésta. Si bien el ocio creativo piede ser ofrecido como un medio de expresión libre y autónomo, paradójicamente puede llevar a la pérdida de libertad en el terreno del ocio creativo y desinteresado colonizado por los discursos de la racionalidad económica”. 
¿Dónde se ubican nuestros informantes en este abanico de combinaciones que se abre entre el trabajo y el ocio, así como entre el componentes ascético que encarna el homo laborans y el hedonista del homo ludens?. Pues, en primer lugar, aunque resulte paradójico, el directivo es quien más importancia da al binomio ocio-hedonismo, dando la impresión de ponerlo por encima del trabajo y el ascetismo, por lo que ocuparía la posición de una postmodernidad fuerte. De todas formas, también se nota que su opinión tiene un carácter resistente frente a la que encuentra en su entorno, por lo que su postmodernidad es más deseada que practicada con comodidad. En cualquier caso, resulta curioso que quien más comprometido está profesionalmente con el capitalismo tenga una opinión o muestre unos valores que ocupan una opinión claramente periférica respecto a dicho sistema. Quizás sea porque el informante ve tan seguro a su sistema (y éste a sí mismo) que se puede(n) permitir el lujo de posicionarse frívolamente en posiciones antisistema. $\mathrm{O}$ quizás revele que el capitalismo busca hoy sus mejores y más comprometidos profesionales fuera del sistema. La razón de esto podría ser, tanto que sus caladeros tradicionales ya no le proveen de lo que hoy más necesita, como que está ávido de experiencias nuevas. Florida estaría más de acuerdo con esta segunda hipótesis ${ }^{14}$. Por eso ha bautizado a la clase creativa como "burguesía bohemia".

Por su parte, la ingeniera nos habla del protagonismo del ocio cuando nos refiere el uso de las redes sociales en su tiempo y lugar de trabajo, aunque no sólo con una finalidad lúdica, pues habitualmente las utiliza para su actividad profesional. Además, también dice clara y contundentemente que no permite al trabajo invadir su tiempo de ocio. Por lo tanto, en este caso tendríamos claramente representada la postmodernidad débil con la que se identifica Florida, pues la mezcla se realiza elevando la influencia en el trabajo de los habitus asociados al ocio y bloqueando el movimiento inverso. Un mismo permiso al ocio para que se introduzca en el trabajo lo observamos en el artista, que aprovecha sus viajes por motivos profesionales a distintas partes del mundo (Nueva York, Tokyo, Chile, México, Europa, etc.) para usarlos vacacionalmente.

Justo al contrario de lo que ocurre con la arquitecta, pues nos confiesa que en sus viajes y vacaciones va observando y tomando ideas para aprovecharlas en su actividad profesional. En este caso es el trabajo el que se introduce en el ocio, por lo que la posición que se ocupa es la de una modernidad débil. De todas formas, el mejor representante de esta posición es, sin lugar a dudas, otra vez, el artista,

14 Es también el caso, por ejemplo, de la imaginación (Appadurai, 1996: 5), tradicionalmente vinculada al arte, el mito y el ritual, que se habría desanclado de esos ámbitos para pasar a convertirse en una parte del trabajo mental cotidiano de la gente ordinaria". El contexto en el que esto tiene lugar es el de un desanclaje global y generalizado de todos los componentes de subjetivación de sus respectivos y tradicionales ámbitos de anclaje. 
pues todas sus actividades físicas e intelectuales con las que ocupa el tiempo libre generan estímulos que luego le sirven en su proceso creativo. Es precisamente por tener esa función tan importante que no está de acuerdo con el uso de la palabra "ocio", que interpreta como la negación del trabajo, entendido éste como algo que produce rentabilidad.

Algo más lejos va el científico, hacia una modernidad fuerte, cuando argumenta que el trabajo ocupa un lugar central en su vida, que no distingue los domingos de los martes, que el ocio es una mera extensión de su actividad laboral y que, en fin, fuera del trabajo sólo hay pérdida de tiempo. En la misma posición de dominio del trabajo y extensión al tiempo de ocio, pero no celebrándolo, sino lamentándolo, se encuentra nuestro abogado. El hecho de que no esté casado, viva sólo y no tenga hijos es algo que, según nos cuenta, probablemente favorezca esta posición. Por lo tanto, lo que le falta no es sólo tiempo de ocio, sino también tiempo familiar, así que la distinción que introduce y contamina a la de trabajo/ ocio es la de trabajo/familia, relacionada, a su vez, con la distinción tiempo productivo/reproductivo.

La separación del tiempo libre, tanto del trabajo productivo como de las tareas familiares reproductivas, es algo de lo que hablan explícitamente la arquitecta (divorciada y con tres hijos menores de 12, 11 y 7 años) y la escritora. Es cierto que esto parece cuestionar la cuádruple partición propuesta al principio, pues el tiempo libre de obligaciones se opone no sólo a la institución laboral sino también a la familiar. Sin embargo, si asumimos que en ambos casos se induce un comportamiento heterónomo en el que el individuo se ve obligado legalmente a asumir ciertas responsabilidades y que esta actitud es distinta a la que tiende a prevalecer en el tiempo libre, pues el individuo tiene más libertad y autonomía, lo que nos encontramos es con el par heteronomía/autonomía, teniendo el primer componente un marcado carácter instituido y siendo el segundo más bien instituyente.

A partir de nuestras conversaciones con los nueve creativos, aunque tuvieron un carácter semiestructurado y no preguntamos de un modo exhaustivo por las actividades de ocio, frecuencia, etc., comprobamos que nos mencionaron 50 actividades, de las cuales 20 son intelectuales, 18 físicas y 12 sociales. Dentro de las intelectuales la lectura es la más importante pues la comparten 7 de nuestros informantes, seguida a cierta distancia del cine y la música, con 4 aficionados cada una. Las actividades sociales están representadas principalmente por los viajes, segunda en el ranking general con 5 informantes que los disfrutan. Finalmente, dentro de las actividades físicas destacan la gimnasia, correr y la montaña, ocupando todas la cuarta posición con 3 practicantes cada una y seguidas con 2 por la bicicleta y el esquí. 
Conviene subrayar que, si bien las actividades intelectuales son las más citadas, el abanico de opciones que nos mencionan dentro de ellas es restringido, pues está formado por apenas 6 actividades, sólo un poco más que las sociales (5), mientras que las físicas llegan hasta 10. Por otro lado, llamamos también la atención sobre el hecho de que nadie menciona el "no hacer nada" como modo de disfrutar el tiempo libre, pues es uno de los principales factores que estimulan el cultivo de la creatividad según Arieti (1976:372-383) En cuanto a la ordenación de los informantes por el número de actividades, si consideramos que la media es 5,5, de las cuales 2 son físicas, 2,2 intelectuales y 1,3 sociales (así que la actividad física doblaría a la social y estaría seguida muy de cerca por la intelectual), podemos ver quiénes están por encima y por debajo.

Ocupa una primera y destacada posición el artista, con 11, además muy bien repartidas ( 5 intelectuales, 3 físicas y 3 sociales). Le siguen con 8 la ingeniera (igualmente bien repartidas: 3,3 y 2 ) y la arquitecta (más desigual: 1 , 4 y 3 ), con 7 el abogado (2, 3 y 2) y con 6 el científico (3, 2 y 1). Estaría ligeramente por debajo de la media el 5 de la publicista $(4,-$ y 1$)$, el 4 de la médica $(2,1$ y 1$)$, el 3 del directivo (-, 1 y 2 ) y el escuálido 1 de la escritora $(-, 1,-)$.

$\mathrm{Si}$ una de las características principales de una sociedad generadora de creatividad es que exponga a sus gentes a diferentes e incluso contrastados estímulos culturales (Arieti, 1976: 312-325), nuestros informantes no parece que estén del todo en esa situación. Como se ve en los datos anteriores, sólo el artista, la médica y la ingeniera tienen un ocio más diversificado, seguidos por el científico y el abogado. La arquitecta, por su parte encabezaría el ranking de falta de diversidad, seguida por la escritora y el directivo.

Finalmente, todos los informantes, salvo la escritora de nuevo, nos dicen que practican más actividades en la actualidad que en su niñez o juventud. Los mayores aumentos los protagonizan la arquitecta y el abogado con 7 actividades más, la ingeniera con 6, el artista con 5, la publicista con 4, el científico con 3, el directivo con 2 y el médico con 1 . En general esas ganancias son mayores en el terreno intelectual y el social que en el físico, donde simplemente tienden a mantenerse $e^{15}$.

Si sumamos las posiciones obtenidas por los informantes en los tres rankings mencionados (cantidad de actividades, diversificación y evolución en relación a la infancia y juventud), comprobamos (Cuadro II) que la ingeniera y el abogado ocupan la primera posición con 6 puntos, seguidos por el artista (7), la arquitecta

15 Esto da la razón a Florida (2002) cuando afirma que los creativos, más que bienes y servicios consumen experiencias. Su característica principal es que son “memorables" y que se incorporan a la personalidad. De ahí la importancia de esa "economía de la experiencia" sobre la que investigan Pine y Gilmore (2000). Verdú (2003) ha reflexionado sobre su fabricación en el "capitalismo ficción". 
(8) y el científico (10). Por debajo de la media $(12,5)$ estarían la publicista (15), la médico (17), el directivo (17) y la escritora (24). Llama la atención que ninguna variable permite explicar este ordenamiento pues no parece afectado por la edad, el género, estado civil, e hijos. Tampoco parece que influya la profesión, pues arriba y abajo están tanto los de ciencias como los de letras, los más y menos artistas e incluso los más y menos vinculados al mercado ${ }^{16}$.

\section{Cuadro II. Ranking de perfiles representados por los informantes en relación} a las prácticas de ocio.

\begin{tabular}{|c|c|c|c|c|}
\hline & $\begin{array}{l}\text { RANKING } \\
\text { GLOBAL }\end{array}$ & $\begin{array}{l}\text { Ranking de } \\
\text { cantidad de } \\
\text { actividades }\end{array}$ & $\begin{array}{c}\text { Ranking de } \\
\text { diversificación de } \\
\text { actividades }\left(^{*}\right)\end{array}$ & $\begin{array}{l}\text { Ranking de variación } \\
\text { juventud-madurez }\end{array}$ \\
\hline Abogado & 6 & 1 & 3 & 2 \\
\hline Ingeniera & 6 & 2 & 2 & 2 \\
\hline Artista (v) & 7 & 3 & 1 & 3 \\
\hline Arquitecta & 8 & 1 & 2 & 5 \\
\hline Científico & 10 & 5 & 4 & 1 \\
\hline MEDIA & 12,5 & & & \\
\hline Publicista (m) & 15 & 4 & 5 & 6 \\
\hline Médico & 17 & 7 & 6 & 4 \\
\hline Directivo & 20 & 6 & 7 & 7 \\
\hline Escritora & 24 & 8 & 8 & 8 \\
\hline
\end{tabular}

$\left.{ }^{*}\right)$ Este es un ranking construido intuitivamente

Volviendo al abanico general de actividades, pero ahora desde un punto de vista cualitativo, llama la atención el hecho de que las físicas e intelectuales, que abarcan casi 4 de cada 5 preferencias, tienden a ser individualistas, mientras que las sociales tienen un peso mucho más bajo. De modo que la clase creativa, según la tenemos representada, por lo que al ocio respecta, se construye en términos predominantemente individualistas. Quizás hasta narcisistas. Esto es importante porque, según Koestler $(1975: 27)$ parte de la creatividad se activa a partir de emociones participativas que trascienden el ego. Nuestros informantes no parece que estén muy abiertos a ese componente.

16 Esta conclusión obliga a cuestionar la importancia que adjudica Bourdieu (1991) a las grandes determinaciones estructurales en la construcción del habitus que se activa en el consumo de ocio. Tiene más razón Lahire (2006: 53) cuando, en contra de las presunciones de su antiguo maestro, asegura que "el mundo social no está nunca tan unificado como para permitir una sola y única escala de legitimidad cultural”. Eso es sólo una idea que viene bien - dice - a los profesores de sociología para hacer más fácil y didáctico su magisterio. En realidad, "los individuos viven una mixtura cultural alternando u oscilando, según los dominios, las circunstancias o los momentos, prácticas legítimas y prácticas menos legítimas” (p. 687). Además, cada individuo puede participar, sucesiva o simultáneamente, en varios grupos o instituciones (p. 60). El resultado no es la desaparición de las determinaciones sino su multiplicación, lo que hace que "cada individuo sea una sociedad vuelta individual" (p. 16). Dicho de otro modo, "la plurisocialización de los individuos en sociedades diferenciadas es la que da razón de la variación interindividual de sus comportamientos sociales” (p. 373). Una critica más general al habitus puede verse en un trabajo más teórico de Lahire (2004: 27 y ss.) sobre la socialización, que culmina con una interesante propuesta; "una sociología de la pluralidad de las lógicas efectivas de acción y de la pluralidad de las formas de relación de la acción” (p. 227). ¿Hay algún profesor de sociología que se haya tomado esto en serio? 
Por otro lado, hay que subrayar la diferencia que se establece entre la actividad intelectual y la física, pues la primera recibe un mayor número de elecciones y ha ganado más importancia al entrar en la vida adulta, pero tiene un abanico de elecciones más restringido que la segunda. Esta relación inversamente proporcional no divide a nuestros informantes sino que se da en el interior de cada uno de ellos. Sus opiniones nos permiten añadir que la actividad física tiene un carácter esforzado e incluso arriesgado que cuesta continuar en la vida adulta, mientras que la intelectual es interpretada en términos más relajados y aumenta con el paso a la madurez. Por lo tanto, la clase creativa se construye a través del desplazamiento (que no sublimación ni eliminación) del esfuerzo físico, que deja un hueco progresivamente mayor al goce intelectual. Es cierto que el esfuerzo físico es necesario, pero lo es más en la vida pasada del creativo, quizás como elemento socializador de cara al desempeño del trabajo, necesariamente esforzado e incluso competitivo. En la madurez tiende a introducirse el divertimento liviano, poco exigente y gratuito que representan las actividades intelectuales (por ejemplo, la lectura). De todas formas, esto no quiere decir, insistimos, que la actividad física desaparezca, pues tiene peso y los informantes no dudan en concedérselo. Ocurre simplemente que su importancia es menor ${ }^{17}$.

Finalmente, las actividades sociales, representadas mayoritariamente por la visita a discotecas, bares, pubs y restaurantes, tienen un carácter hedonista que está en las antípodas del ascetismo y del individualismo que exige la mayor parte de la actividad física elegida, aunque en general congenie con su narcisismo. Adquiere peso con la edad, como la actividad intelectual, por lo que el creativo deducimos que la demanda en su madurez y, aunque sea como válvula de escape, debe resultarle útil para su actividad.

Según nuestros informantes, esta actividad social cumple una doble función. Por un lado, permite mantener y cargar el contacto con los amigos. En términos generales, podemos decir que así se garantiza la autopiesis social: la producción de la actividad social (el estar juntos) que nos constituye. En relación a la creatividad ello implica que estar-uno-con-otro es un importante combustible y puede que incluso una imprescindible materia prima. De hecho Florida (2009: 128) dice del trabajo creativo que exige un entorno de bares y restaurantes en los que la gente se junte y forje relaciones sociales. Son los "terceros lugares", opuestos

17 En este sentido, nuestros informantes se apartan ligeramente del Fitness and Health, que comenzó en los años 70 pero que tiene su origen en los años 40, cuando el ejército decide mejorar la calidad de sus reclutas (Howell e Ingham, 2001: 335). Tampoco terminan de encajar en esa importancia que Sloterdijk (2012) concede al "ejercicio" en el siglo xxi (que sustituye a la "reflexidad" del xx y a la "producción" del xix), un tipo de "antropotécnica" que los individuos de distintas culturas han intentado optimizar para conjurar los riesgos de la vida y las certezas de la muerte (p. 24). Una consecuencia de ello es, según Sloterdijk, la aparición del “neoatletismo", inaugurado por el olimpismo de Pierre De Coubertín. Con él desaparece la "religión del hambre" y aparece la de "la saciedad y el fitness" (pp. 117-118). Como decimos, nuestros informantes no obedecen esta ascética tendencia. 
tanto al hogar como al trabajo. Se caracterizan por ser lugares de serependity (encontrar lo que no se busca), que dan lugar a barrios densos y diversos (Borja, 2009: 20). Igualmente son el hogar del cotilleo, "la base de la democracia", según Rodríguez Villasante (2006: 272).

Por otro lado, estas actividades facilitan también un tipo de autopiesis distinta, de tipo estético, pues permiten ser observadores de un espectáculo que como actores contribuyen también a producir. Este juego simétrico y estético de miradas es también un importante combustible y materia prima existencial. Así lo reconocía nuestra arquitecta a propósito de sus salidas a las discotecas.

Si las emociones autoafirmativas, como la agresividad, derivan de reacciones de emergencia e implican un vaciado de la conciencia, las emociones participativas, más involucradas en las actividades de ocio sociales, tienden a expandir la conciencia hacia ese "sentimiento oceánico" del que hablaba Freud (1982) cuando se refería a la experiencia de lo religioso. El llanto es la manifestación de emociones participativas frustadas, mientras que la risa expresa las autoafirmativas. Las causas de aquél tienen todas en común "el cuestionamiento de las fronteras aislantes del individuo para entrar en una comunión simbiótica con seres humanos o alguna entidad superior real o imaginaria de la cual el sí mismo se siente parte" (Koestler, 1976: 299). Está participación está muy desarrollada en el niño, que tiene fronteras egoicas muy fluidas, pero será parcialmente relegada a los estratos inconscientes en la edad adulta. De un modo similar, los vínculos participativos de la magia primitiva serán gradualmente transformados en rituales simbólicos, épicas mitológicas y otros modos de ilusión Sin embargo, es en ese lugar infantil y primitivo donde el artista y el místico obtienen su inspiración (p. 300).

Por eso el ocio colectivo es tan importante en la construcción social del creativo. La actividad intelectual, en cambio, no lo es tanto debido a su carácter individual. En este sentido, conviene recordar que la literatura, a la que se entregan mayoritariamente y con bastante intensidad nuestros informantes, tiene su origen en "el crepúsculo del misticismo y de la mitología", que lo es también del reinado del sentimiento de participación. Y es que, como los primeros literatos "tenían menos medios para impresionar a sus audiencias", procedieron a enmascarar, pintar y dramatizar sus cuentos (Koestler, 1976: 309). De todas formas, aunque el novelista utiliza otras técnicas, en el fondo también continúa rigiendo en su obrar - dice Koestler- la magia simpatética. De un modo menos visible y explícito pero quizás igual de efectivo.

¿Puede ser esta la razón de que nuestra escritora tenga un ocio (tendente a la individualización) tan escaso y poco variado? ¿Para qué lo necesita como estímulo existencial si con la magia interior (de carácter inevitablemente social) que 
alimenta su creatividad literaria le basta? Si esto fuera cierto, la riqueza y variedad de ocio (insistimos, tendente a la individualización) tendría una relación inversamente proporcional con las aptitudes creativas (necesariamente sociales). Dicho de otro modo, el ocio (individualizante) se vuelve importante a la hora de estimular la creatividad allá donde... hay poca cosa (socializante) que estimular ${ }^{18}$. Ya en general, podríamos añadir que la propia noción de clase creativa es un indicio... de la decadencia de la creatividad.

Dice Florida (2004) que los miembros de la clase creativa se caracterizan por tener una "hipermovilidad horizontal", pues cambian de trabajo cada 3,5 años ${ }^{19}$. Esta característica en principio sorprende pues, según Gardner (2010ः 475), "a un individuo le lleva 10 años conseguir el dominio inicial de un campo" y rara vez pueden documentarse descubrimientos significativos antes de que se haya cumplido una década de actividad sostenida" (p. 60). Tal es la conclusión que extrae tras investigar las vidas de 7 importantes personajes del siglo xx. En cierto modo, estas consideraciones se ven confirmadas por Farrell (Noya, 2010ः29), pues ha observado que los grupos de impresionistas franceses y de otros movimientos artísticos y literarios duraban entre 10 y 15 años, lo que da a entender que en ese tiempo habían generado toda la creatividad de la que el grupo era capaz.

En nuestro caso, si tomamos nota de las trayectorias laborales que confiesan nuestros informantes, comprobamos que destacan por su hipermovilidad la arquitecta y el artista pues ambos acumulan 8 trabajos anteriores al actual. Lo hacen, además, combinando una vida familiar exigente pues ella tiene 3 hijos (todavía a su cargo) y él dos (ya mayores). Sin embargo, este entorno familiar parece más duro para ella pues está divorciada y él permanece casado. Las trayectorias laborales de ambos, si bien son las más extensas de nuestros informantes, difieren en su variedad. En efecto, el artista tuvo 3 trabajos poco cualificados y temporales o a tiempo parcial en sus inicios (camarero, vendimiador y almacenista), luego 2 actividades especializadas y a tiempo completo (profesor de educación física y actor) y finalmente 3 trabajos relacionados con su profesión actual. En cambio, los trabajos de la arquitecta, iniciados ya antes de acabar los estudios y que parecen haber sacado provecho del boom constructor de los últimos 15 años, son todos muy similares y están relacionados con su profesión actual. Por lo tanto, el artista se beneficia de una vida familiar más apacible y tiene una vida laboral más rica.

18 Este tipo de argumentación no debe parecer extraño. Harpur (2007: 191) lo utiliza cuando sugiere que los seres sobrenaturales (duendes, extraterrestres, vírgenes, etc.) se le aparecen a "las personas que no tienen una relación consciente con la realidad daimónica” (p. 191) Por el contrario, quienes siempre han tendido puentes hacia ella no reciben esas llamativas y exageradas visitas.

19 Sólo la arquitecta, con apenas 2,5 años en su actual trabajo y la ingeniera con 4 se acercan a esa media. Le siguen la publicista con 9, luego el directivo (12) y la escritora. Finalmente tenemos al artista (20) y el científico. 
Justo al revés que la arquitecta. También se diferencia en que el primero tiene una formación humanista o de letras y la segunda técnica.

En un escalón por debajo nos encontramos a la publicista y a la ingeniera, ambas menores de 40 años y con 4 trabajos, además del actual, en su currículum. Curiosamente se reproduce la tendencia vista en el peldaño superior pues la que tiene formación humanista exhibe una experiencia más variada ( 1 trabajo inicial temporal poco cualificado y 2 cualificados desarrollados en distintas empresas o centros) que la de la técnica (lo único que ha hecho en sus trabajos es ascender: de programadora a consultora pasando por analista). Conviene añadir que esa mayor variedad de la publicista se da en un contexto familiar algo más exigente que el de la ingeniera, pero menor que los informantes anteriores, pues tiene un hijo. Por otro lado, es importante hacer notar que su actividad profesional actual está ocupada por dos actividades absolutamente distintas, la publicidad y la medicina china.

En un tercer escalón podemos ubicar a la escritora y a la médica, ambas con 3 actividades laborales a las espaldas, pero la primera algo más rica (combina 2 trabajos temporales iniciales con uno más profesionalizado pero distinto de su actividad actual) que la segunda (sus trabajos anteriores son temporales o a tiempo parcial y poco cualificados). Además, combina la dedicación a la escritura con un trabajo en el Consejo Español para la Acogida de Refugiados, mientras que la médica se ve absorbida desde hace 3 años por su trabajo como residente en un hospital. Por todo ello, la escritora debe ubicarse algo por encima. También se cumple aquí que la formación humanista genera una experiencia laboral más variada. En cambio sus vidas familiares son idénticas: tienen pareja pero no hijos.

En él cuarto escalón nos encontramos con el directivo y el abogado, ambos mayores de 40 años, sin vida familiar compartida y con una experiencia muy reducida: el directivo como educador social y el abogado simplemente dedicó un tiempo a preparar oposiciones.

Finalmente, el científico, casado, con dos hijos y mayor de 40 años, no nos consta que haya tenido otras actividades fuera de su vínculo con la Universidad.

En definitiva, observamos que, si bien las profesiones técnicas proporcionan experiencia, la variedad está más vinculada a la formación humanista y a una vida familiar también más rica, independientemente de la edad. También comprobamos que las mujeres parecen ser superiores a los varones en esto de la variedad, que tiene su influencia en la calidad del currículum, quizás por la misma razón que su éxito escolar es también mayor y su presencia en estudios universitarios superior: la exigencia de superar la desigualdad estructural que padecen (Bergua, 2009). Este problema, como es sabido, no es algo que afecte sólo a España. En Es- 
tados Unidos el 96\% de los puestos de trabajo con ingresos superiores a 150.000 dólares los ocupan hombres blancos y en Europa sólo un 5\% de los altos cargos de las empresas los ostentan mujeres. Ocupa la primera posición Suecia con un $11 \%$ y España la última con el $2 \%$. Por otro lado, es conocido que las mujeres padecen más que los hombres la precariedad laboral, el desempleo, los bajos sala$\operatorname{rios}^{20}$ (un 17,3\% inferiores a los de los hombres en España) y, además, practican la doble jornada (trabajan fuera y en casa). Finalmente, no deberíamos olvidar que hay también una desigualdad social que afecta a separadas, divorciadas, tercera edad, inmigrantes y prostitutas. Todo ello, aunque de diferentes maneras, es probable que influya en el carácter laboralmente más esforzado de las mujeres.

Cuadro III. Ranking variedad e intensidad ocio y trabajo

\begin{tabular}{|ll|c|c|c|}
\hline & & $\begin{array}{c}\text { RANKING } \\
\text { GLOBAL }\end{array}$ & $\begin{array}{c}\text { Ranking } \\
\text { trabajo (*) }\end{array}$ & $\begin{array}{c}\text { Ranking } \\
\text { ocio (**) }\end{array}$ \\
\hline Arquitecta & Mujer, +40 años, divorciada, 3 hijos, Barcelona & 1 & 1 & 4 \\
\hline Artista (v) & Varón, +40 años, casado, 2 hijos, Huesca & 1 & 2 & 3 \\
\hline Ingeniera & Mujer, -40 años, separada, sin hijos, Bilbao & 2 & 4 & 2 \\
\hline Publicista (m) & Mujer, -40 años, casada, 1 hijo, Madrid & 3 & 3 & 6 \\
\hline Abogado & Varón, +40 años, soltero, sin hijos, Compostela & 3 & 8 & 1 \\
\hline Médica & Mujer, -40 años, casada, sin hijos, Bilbao & 4 & 6 & 7 \\
\hline Escritora & Mujer, -40 años, casada, sin hijos, Madrid & 5 & 5 & 9 \\
\hline Científico & Varón, +40 años, casado, con hijos, Compostela & 5 & 9 & 5 \\
\hline Directivo & Varón, +40 años, soltero, sin hijos, Zaragoza & 6 & 7 & 8 \\
\hline
\end{tabular}

( ${ }^{*}$ Medido por la cantidad, variedad y especialización de los trabajos desempeñados. **Véase Cuadro XI. En color rojo las cifras superiores a la media y en azul las inferiores. En color gris las puntuaciones homogéneas y superiores a la media, en azul las homogéneas pero inferiores a la media, en amarillo las heterogéneas y en blanco las intermedias en los dos sentidos.)

Si comparamos la clasificación de las actividades laborales con la que obtuvimos en el análisis del ocio, es posible distinguir tres grupos de informantes (cuadro III). Primero, aquellos que puntúan bien en ambos apartados y, en consecuencia, tienen una vida de ocio y laboral tan variada como intensa. Se trata del artista y la arquitecta, seguidos por la ingeniera. En segundo lugar, están quienes puntúan mal en ambas actividades y su vida, por lo tanto, es bastante ligera desde este punto de vista. Son la médica y el directivo. Finalmente, están quienes compaginan riqueza en un lado y liviandad en el otro, caso del abogado (al que salva su ocio) y de la escritura (redimida por su trabajo). La publicista estaría en un punto medio entre los homogéneos y los heterogéneos con su tercera posición en trabajo y su sexta en ocio. También se comprueba que las mujeres tienden a ser más homogéneas (la excepción es la escritora) y los hombres más heterogéneos

20 La apuesta por los estudios apenas arregla esto pues por cada año adicional de escolaridad, el salario de ellas aumenta, caso de España, un 6\% por un 5\% el de los varones (Bergua, 2012). 
(salvo el artista) y que una vida familiar intensa sienta bien para compaginar buenas puntuaciones en trabajo y ocio (salvo al científico -bien de familia pero con un balance ocio/trabajo heterogéneo-). Es como si las vidas familiares, de ocio y trabajo se retroalimentaran. De todas formas, aunque las buenas puntuaciones impliquen intensidad y variedad, eso no significa que sean cómodas ni fáciles de llevar.

Si dejamos las trayectorias laborales y nos fijamos en las características de los trabajos actuales comprobamos que hay dos aspectos que todos nuestros informantes mencionan, aunque contextualizándolos y valorándolos de modos diferentes: la retribución y los horarios. En relación a los ingresos que les procuran sus actividades, todos están de acuerdo con ellos. Por lo que respecta a los horarios, parece que varía la cantidad de horas trabajadas y la flexibilidad a la hora de repartirlas, aunque siempre se trabaje con intensidad. Combinando esas dos variables nos encontramos con muchas posibilidades y contrastes.

La ingeniera, por ejemplo, confiesa que trabaja "mil horas, menos de 10 nunca”, pero que no le parece demasiado pues está acostumbrada. En cambio para la médica es "horrible" pues las guardias de 24 horas que tiene cada 6 días hacen que sus padres y amigas incluso se enfaden con ella. Ambas, la ingeniera y la médica, trabajan mucho y son poco flexibles pues el trabajo lo dejan atrás cuando llegan a casa. La primera porque así se lo ha propuesto. La segunda, por fortuna para ella, porque no puede hacerlo.

Aunque esta tendencia a trabajar mucho sea general, algunos de nuestros informantes han logrado reducirla pero manteniendo algo de libertad o flexibilidad. Es el caso de la escritora, que hace 40 horas a la semana y tiene libertad para distribuirlas e intentar disponer de tardes libres. Igual de feliz se muestra la arquitecta, con un horario similar y también algo flexible que le ha liberado de las jornadas estresantes de 12 horas que tuvo durante el boom. Dice para ilustrarlo: "yo me había pasado doce años intentándome apuntar a un gimnasio y no había manera... ahora lo he conseguido". En la misma dirección de haber logrado contener el horario van las valoraciones del artista, que reconoce tener jornadas "muy, muy intensas", pero que ya no le roban ninguna hora por las noches, por lo que no debe padecer el sufrimiento del día siguiente, ni tampoco le ocupan los fines de semana, al menos el domingo.

Otros, en cambio, aunque no hayan trabajado mucho, siempre han tenido horarios muy flexibles que podían abarcar cualquier parte del día y no les importa e incluso lo ven normal, como ocurre con el directivo, que suele decir a su entorno para convencerlo: "si pensáis que de 8 a 3 ocurren los problemas, ni idea de lo que ocurre en el mundo". De igual modo opina quien más lejos ha llevado la 
flexibilidad en este ámbito, el científico, pues en su equipo "todos tienen horarios absolutamente flexibles y no me tienen que pedir permiso si no vienen mañana". Y es que, como ya dijimos más arriba, uno de sus objetivos desde que empezó a trabajar era precisamente "tratar de no diferenciar demasiado un sábado de un martes" e incluso se obligaba a ello yendo un martes a la playa y un domingo a la facultad. Esta mezcla del ocio y del trabajo hace que el científico se lleve trabajo a casa (los exámenes, la preparación de las clases y la corrección de trabajos) y que en el despacho, por ejemplo, acepte que le llamen para tomar un café o simplemente conversar. Esta absoluta flexibilidad tiene que ver con la enorme libertad que, según opina, tiene su profesión y que lleva al extremo de que "un profesor universitario, si quiere, no trabaja". Finalmente, también es flexible el horario de nuestro abogado, que igualmente se lleva trabajo a casa, pero no porque en este caso se ejerza ninguna libertad sino por las exigencias y ritmos que le vienen impuestos de fuera (plazos, señalamientos, etc.).

Además de la retribución y los horarios, nuestros informantes hablan de otros aspectos del trabajo, algo más complejos pues incorporan varias dimensiones. Sin embargo, en nuestra opinión, como la mayoría tienen que ver con la gestión de las gentes, sean clientes, equipos, intermediarios, compañeros, etc., disolveremos dichas dimensiones en las relaciones con otros, en el ser-uno-con-otro (Nancy, 2000; Sloterdijk, 2003). Quiere esto decir que entendemos que la materia prima sobre la que se trabaja y de la que brota la creatividad de nuestros informantes es siempre vincular, sociabilitaria ${ }^{21}$. Nos tomamos este aspecto en serio porque al hablar del ocio ya subrayamos el carácter social y colectivo de la inspiración, por más que esté en el inconsciente. Aquí volvemos a ello, pero para ver esa actividad social en el proceso de trabajo.

Sobre su importancia en el mundo creativo tal cual lo representa el arte ha escrito Becker (1982: 1-39). En su opinión "todo trabajo artístico, toda acción humana, involucra la unión de, a menudo, un gran número de gente" y "el trabajo siempre muestra signos de esa cooperación". Lo que el autor denomina "mundo del arte" "existe en la acción cooperativa de esa gente". Por otro lado, en su análisis sobre el artesano como paradigma de un modo de trabajar distinto y quizás necesario en nuestra época, Senett (2009: 304-305) dice que es un "experto sociable".

Proponemos tratar en los mismos términos el mundo de los creativos. Sin embargo, igual que ocurriera al tratar el ocio, nos vamos a encontrar con el hecho de que nuestros informantes tienen una posición ambigua e incluso paradójica,

21 Como dicen Hardt y Negri (2000), "Participamos en un mundo productivo hecho de redes sociales y comunicacionales, servicios interactivos y lenguajes comunes". Hoy lo que se produce es menos bienes y servicios que cooperación y comunalidad cooperativa. Cada bien y servicio tiene en su interior el socius, lo común, el "con" del ser-uno-con-otro. Por eso "lo común es la producción y la liberación de la multitud". 
pues la amistad, en tanto que expresión de ese sustrato vincular, si bien les atrae, no es menos cierto que también la evitan o simplemente la tienen controlada instrumentalmente. Por lo tanto, como ocurrió en el ocio, nos encontraremos a individuos, a veces representándose a si mismos y otras envueltos en otros ropajes, que piden tanto como rechazan el vínculo con los otros.

La importancia del trabajo en equipo es un asunto que subraya de un modo más bien romántico y algo contradictorio, nuestra publicista. Aunque reconoce que sus experiencias pasadas en media docena de equipos no han sido todas buenas, ahora que trabaja sola lo echa de menos. Como ella mismo dice, "la suma de todos, aportando (cada uno) su cualidad produce una sinergia" que "es algo mucho más grande que lo que uno puede hacer solo, ¿no?”. Más allá de la utilidad del grupalismo parece que echa de menos el crecimiento en uno que puede generar el estar-con-otros.

Este rasgo encuentra su máxima acentuación en el científico, que busca convertir las relaciones de colaboración en relaciones de amistad para que así el trabajo y la interdisciplinariedad, para él fundamental, salgan mejor adelante. Como confiesa: "En mi experiencia, las relaciones de trabajo que salen bien, son las que haces con amigos". Por eso, aunque realmente ocupe una posición superior, intenta ser más bien coordinador, reconocer que los nuevos que se incorporan, aunque tengan 23 años, son adultos como él e incluso saben más. También hay que admitir las personalidades diferentes, pues en el grupo caben tanto el "creativo", que no aguanta dos veces repitiendo la misma reacción, porque se cansa, como el que es más "metódico", o tanto el que "va en plan tractor" como el que es más bien "un camión". Esto no siempre resulta fácil de sobrellevar porque "muchas veces también tienes que ceder" o "tienes que ir a acompañar a alguien cuando, igual, estabas mejor echando la siesta". En cualquier caso, es mucho mejor que soportar a los compañeros que no son amigos y que pueden convertirse en competidores, como ocurrió cuando su pequeño departamento se agrandó, llegó mucha gente, algunos con buenos currículum, no fueron generosos, aparecieron problemas derivados de esto "y hubo que dar pelea". Este episodio que ocurrió en la época de implantación de la LRU (es decir de cuando nuestro informante tenia 25 años y se iniciaba en la investigación, a mediados de los 80) muestra que la defensa de la amistad no obedece tanto a los valores intrínsecos que pueda tener sino a los males que irrumpen cuando no está y sólo hay competencia y agresividad. Por otro lado, la amistad tampoco es con gente muy distinta pues, aunque trabajen compuestos y moléculas diferentes, y haya cierta interdisciplinariedad, son todos químicos y las posibilidades de feeling mayores. De modo que la apuesta por la amistad no es un valor intrínseco sino que encubre, en realidad, miedo al afuera. 
El artista, con un trabajo también muy individualista, está acostumbrado a generar equipos en cada proyecto, pero no habla de esa dimensión tan íntima que genera el estar uno-con-otro al que la publicista aludía románticamente y con la que el científico más bien engañaba. Todo es más profesional. Igualmente, cuando habla del elemento humano exógeno, los clientes, la potencia que pudiera tener el vínculo con ellos queda subsumido en una fuerza más poderosa e incluso mística que es el trabajo, pues "cuando tú desarrollas tu trabajo potencialmente creativo, el trabajo se mueve solo y ese moverse solo el trabajo es el que llama a otros clientes y el que llama a otros trabajos". En el caso del artista, ese misticismo de la sociabilidad sobre la que la publicista llamaba la atención está pues en otro sitio, en su propio ego. Por eso dice "mi equipo soy yo mismo".

El individualismo del artista, aunque más atemperado, se puede observar también en la arquitecta, que agradece un contacto más distendido e igualitario con sus compañeros de trabajo actuales, que incluso le gusta cambiar impresiones con ellos sobre algunos asuntos relacionados con el trabajo, pero que, "claro, al ser ingenieros y arquitectos" no parece que puedan entenderse, pues miran las cosas de modos diferentes. Aquí el ego está profesionalizado y argumenta técnicamente pero no deja de ser ego y desde esa posición tiende a enfriar el vínculo. Pero es que esta desconfianza, si seguimos las opiniones de nuestra arquitecta, se extiende al trato con los propios colegas de profesión pues, aunque siempre está la posibilidad de que el vínculo se torne expresivo es necesario tenerlo contenido, en este caso con el dique de la profesionalidad.

También de un modo positivo valora al grupo la ingeniera y también utilitariamente. Sin embargo, su experiencia no es tan buena, quizás debido a que no trata con iguales sino con subordinados, o quizás por la propia naturaleza del vínculo utilitario, o también por su formación absolutamente técnica, etc. Por eso habla con frialdad de ciertos "perfiles de personas" que tienen "miedo a lo desconocido" y "se ponen a la defensiva", lo que exige - opina-identificarlos y neutralizarlos para que el proyecto salga bien. Como ella mismo dice, hay que "calar a las personas y saber quién es prescindible y a quién no le tienes que pedir información porque sabes que no te va a aportar nada.... El feeling que la ingeniera no tiene con los subordinados de dentro lo encuentra con los clientes de fuera. Pero el trato tampoco es de igual a igual pues unas veces aparece en su discurso como alguien que debe ser instruido y enseñado, por lo que el despotismo al que se tiende con los subordinados se torna paternalismo, mientras que otras es ella la que debe hacer caso pero de un modo muy mecánico, "parametrizando" las demandas que recibe, por lo que el ser uno-con-otro también queda disminuido. En fin, que tanto dentro como fuera, la ingeniera nunca trata con gente, sólo con 
subordinados, ignorantes o demandas que ella se encarga de mecanizar. Estamos ante esa "pericia antisocial" de la que habla (Sennett, 2009: 307) y que se caracteriza por "generar desigualdad entre el experto y el no experto", al que "humilla y acosa mediante críticas".

En esta misma dirección parece apuntar el directivo cuando confiesa que sus mayores problemas tienen que ver la gestión de recursos humanos, la creación de equipos y, sobre todo, la resolución de problemas relacionales o, como él dice,"las relaciones humanas". El elemento humano confiesa que se resiste a sus intentos de administración, pues "cuando intentas ser racional, acaba uno muy quemado". De nuevo aparece la gente como algo exterior y objetivado que exige un particular manejo.

En cambio la médica, que tiende a trabajar más de igual a igual y desde dentro, valora de un modo menos desconfiado a la gente con la que trabaja y por eso entiende que debe haber "flexibilidad mental". Primero, porque hay que llevarse bien con los compañeros para facilitar la convivencia, lo que permite poner de nuevo sobre el tapete del análisis el importante papel que juega, más allá de la grosera utilidad productiva, el con del ser-uno-con-otro. Segundo, ya en términos profesionales, porque "también es muy importante que uno sepa que tiene sus limitaciones y que está trabajando con otras personas y que muchas veces tú no tienes la solución, pero el de al lado sí la tiene, ¿no?”. Por otro lado, los pacientes con los que trata, aunque haya protocolos rigurosos, muchas veces exigen tratos diferenciados que sean sensibles a su singularidad. Como aquella señora claustrofóbica que no quería bajar por el ascensor y obligó a saltar el protocolo. A diferencia de lo que ocurre con la ingeniera, la médica, por su profesión, trata más directamente con la sociabilidad y las gentes. Estamos pues ante puntos de vista profesionales distintos.

El abogado nos descubre una posición nueva pues, aunque trata con gente que es siempre exterior, ya que es el único habitante y dueño del despacho en el que trabaja, tiene con ella una relación cordial e incluso amistosa. De hecho, con los propios clientes, que unas veces le hacen sentir mal porque son difíciles y otras le generan satisfacción porque "ves a la persona contenta y el tema ha ido bien”, debe haber siempre, en su opinión, una relación de confianza. La expresividad del vínculo aparece más fresca que en otros informantes. Esto a pesar del contexto mercantil en el que se desenvuelve y que tiende a ver al cliente como un sujeto incapaz de feeling, ya que "lo único que quiere es que le den razón en el pleito". Seguramente, aunque nuestro informante no lo dice, el cliente tiende a ver al abogado igual: lo único que quiere es el dinero. Las dos son posturas típicas de una relación mercantil. Del mismo modo, el encuentro con el juez y la otra 
parte es competitivo, aunque aquí por razones jurídicas, pues uno sólo trata de "convencer al juez y la parte contraria pide que le den la razón a ella". Es "como una carrera, como un combate" y esto convierte el trabajo en algo "estresante". Sin embargo, nuestro abogado opina que para hacer más llevadera esta situación "es mucho mejor que el abogado de una parte y de la otra se traten y tengan una buena relación entre ellos en lugar de ser enemigos acérrimos". Así "sale ganando todo el mundo". Lo contrario "haría todavía más complicado el caso". Es pues necesaria una relación "cordial" en lugar de amistosa pues no debe ir más allá del compañerismo. Como en el caso del científico nos encontramos con un vínculo aparentemente expresivo pero que es instrumentalizado. Esto es lo máximo a lo que parece poder llevar el ser-uno-con-otro en un contexto de trabajo. Lógico, pues sólo en las relaciones de amistad puede encontrarse lo que nuestros informantes piden pero no dan. Allí el problema es otro: que la expresividad de la amistad sea instrumentalizada.

Por lo tanto, nuestros informantes ubican sus vínculos con los otros en un continuum cuyos extremos serían la amistad pura con relaciones absolutamente expresivas y la relación contractual pura de carácter instrumental. En el primer lado tiende a primar el socius y en otro el ego. En medio aparecen dos posiciones. Por un lado, la utilización del ego que se realiza desde el socius. Por otro, la instrumentalización de la sociabilidad que realiza el ego. La primera nos la encontraríamos fuera del trabajo, en contextos donde predomina la amistad. La segunda estaría en ámbitos profesionales dominados por egos. Tales egos están construidos a partir de formación, competitividad y poder. Nuestra conclusión es que, si bien la individualidad de nuestros creativos pide o reclama sociabilidad pura o expresiva, entendemos que para realizar su trabajo creativo, sus egos no permiten abandonarse a ese impulso y lo tienen contenido, instrumentalizado.

El resultado de tan contradictorios impulsos bien podrían ser esos "vínculos débiles" que Florida (2002: 15) detectó en las vidas de clase creativa norteamericana y que también son la auténtica infraestructura de las flexibles y fluidas sociedades contemporáneas. En efecto, los vínculos más productivos no son los «fuertes» (personas a las que se ve con mucha frecuencia) sino los «débiles» (individuos con los que apenas se tiene contacto o hace mucho que no se ven) (Granovetter, 2000: 48-49). Es lógico que así sea pues «aquéllos con quienes estamos débilmente vinculados son más propensos a moverse en círculos distintos al propio $y$, por tanto, tendrán acceso a una información diferente de la que nosotros recibimos». De modo que los vínculos débiles permiten al individuo abrirse a otros contactos y a las distintas redes de las que forman parte conectarse entre sí. Gracias a estos semidesconocidos la sociedad es una red de redes. 
Por otro lado, los vínculos horizontales que, salvo contadas excepciones (la ingeniera), tiende a cultivar la clase creativa y que se caracterizan por ser contrarios a la autoridad y a la jerarquía, parecen ser también enormemente importantes en la esfera económica.

\section{Conclusiones}

Si es cierto, como doce Florida, que los miembros de la clase creativa compaginan el ocio y el trabajo sin distinguir muy bien dónde empieza uno y dónde acaba el otro, en nuestra investigación comprobamos que esa característica la cumplen la arquitecta, la ingeniera y el artista. Las primeras representan el polo, componente o vector técnico de la clase y el segundo el componente bohemio. Ambos polos muestran también una vida de ocio y laboral tan variada como intensa. En general, esta característica la representan mejor las mujeres que los hombres y está también relacionada con vidas familiares intensas. Por lo tanto, da la impresión de que la familia, el trabajo y el ocio son tres asuntos que crecen y se influyen entre sí dando lugar a las vidas intensas que caracterizan a los componentes más dinámicos de la clase creativa ${ }^{22}$.

En relación al ocio comprobamos que el binomio bohemio-técnico también funciona y que ninguna otra variable parece tener tanta influencia. También vimos que, en relación a este asunto, la clase creativa se construye en términos predominantemente individualistas, pues las actividades más importantes, tanto intelectuales como físicas, tienen este carácter. Por otro lado, es importante subrayar que en la biografía de los creativos el ocio intelectual quita protagonismo e incluso termina venciendo al físico. La otra clase de actividades de ocio, las sociales, aunque no sean muy importantes en la clase creativa, si que lo son en términos globales, pues facilitan una autopiesis de carácter social (construyen al individuo que constituye lo social) a la que se añade otra autopoiesis de carácter estético (generan los actores que constituye lo social como espectáculo). Finalmente, hemos visto que el carácter predominantemente individualista del ocio guarda una relación contradictoria con las aptitudes creativas, pues éstas tienen un tono inevitablemente social, ya que están inspiradas por emociones de tipo participativo y no por las autoafirmativas, que son precisamente las que generan individualidad. De modo que la creatividad está vinculada a actitudes individuales más que sociales.

22 En este sentido, no encontramos el "pacto fáustico" del que habla Gardner (2010:74) en su estudio de siete grandes personajes (Freud, Einstein, Picasso, Stravinsky, T. S. Elliot, Martha Graham y Gandhi): "estaban tan embebidos intentando llevar a cabo la misión de su obra que lo sacrificaron todo, especialmente la posibilidad de una existencia personal plena". Esto es lo que se escondía tras ascetismo y autoaislamiento. Cada uno de ellos "escogió" la perfección de la obra por encima de la perfección de la vida" (p. 466). 
Por lo que respecta al trabajo observamos una contradicción parecida pues, si bien los informantes huyen de las jerarquías de los organigramas y buscan las relaciones horizontales intensas, tanto con los de dentro como con los de fuera, debido a que estimulan la creatividad, no cesan de repelerlas, evitarlas o controlarlas encastillándose en el yo. Estamos entonces ante egos muy potentes y recelosos que, sin embargo, tienen cierta vocación social y el anhelo de una amistad que quizás sobrevaloran. De nuevo el binomio técnico-bohemio expresa a la perfección esta característica. Como hemos sugerido, el resultado de tan contradictorios impulsos son los "vínculos débiles", responsables tanto de la fluidez de las sociedades contemporáneas, como de la anarquía que las empresas temen tanto como necesitan e incluso de las redes (no sólo económicas) en las que dichas empresas y los profesionales se desenvuelven. De modo que las contradicciones, a la vez que encarnan cierta polaridad y por lo tanto diversidad, abren la puerta al incremento de la heterogeneidad. Finalmente, observando las trayectorias laborales hemos detectado que las más ricas e intensas están influidas, otra vez, por los componentes técnico y bohemio, pero que también influye la formación humanista y una vida familiar intensa. Por otro lado, sólo el polo bohemio (representado aquí por el artista y la escritora) ha logrado cumplir su objetivo de reducir y flexibilizar las jornadas laborales, algo importantísimo para la clase creativa pues, como dice Florida (2002: 13) "no pueden ser forzados a trabajar".

En definitiva, ya en general, podemos concluir que, efectivamente, la diversidad y heterogeneidad sociales son importantes en la construcción social del creativo. Florida tenía, sin duda, una buena intuición, pero no la supo trasladar a sus mediciones cuantitativas debido a que el indicador que debía hacerlo, la tolerancia, no alcanzaba a dar cuenta de dicha diversidad. En cambio el estudio de las vidas de los creativos sí que lo permite. Tanto por la vía de la diferenciación y el consiguiente abanico de opciones de vida que se despliega ante los sujetos que hemos entrevistado, como por sus elecciones e igualmente por la de la borrosidad, hibridación y mezcla de lo distinguido, parece claro que nuestros informantes, en primera instancia, y la clase creativa, en general, cabalgan sobre la heterogeneidad. 


\section{Bibliografía}

Appadurai, A. (1996): Modernity at large, Minneapolis: University of Minesotta Press.

Arieti, S. (1976): Creativity. The Magic Synthesis, New York: Basic Books.

Banks, M. (2009): "Fit and Working Again? The Instrumental Leisure of the Creative Class", Environment and Planning, vol, 41, pp. 668-681.

BATAille, G. (1987): La parte maldita, Barcelona: Icaria.

BÁEz, J. M., Bergua, J. A., y Pac, D. (2014) “The creative class and the creative economy in Spain", Creative Research Journal, 26(4), pp. 418-426.

Becker, H. S. (1982): Art Worlds, Los Angeles: University of California Press

BELL, D. (1987): Las contradicciones culturales del capitalismo, Madrid: Alianza

Bergua, J. A. (2009): Sociología de la política, Zaragoza: Mira.

- (2012): Érase la sociedad. Una aproximación sociológica, Madrid: Editora Nacional.

Bourdieu, P. (1991): La Distinción. Criterios y bases sociales del gusto, Madrid: Taurus.

- (1997): Razones prácticas, Barcelona: Anagrama.

Caillois, R (1967): Les jeux et les hommes. Les masques et le vertige, Paris: Gallimard.

Csikszentminalyi, M. (1996). Creativity: Flow and the Psychology of Discovery and Invention, New York: Harper Perennial.

Culler, J. (1992), Sobre la deconstrucción. Madrid: Cátedra.

De Bono, E. (2006): El pensamiento lateral, Barcelona: Paidós.

De Lucas, A. (1995), Proyecto docente. Sociología. Sociología del consumo e Investigación de mercado, Madrid: Facultad de Ciencias Políticas y Sociología de la UCM (Proyecto de docencia presentado para concurso de acceso a la plaza de titular. Inédito).

De Miguel, J. M. (1996), Auto/biografías. Madrid, CIS.

Dumazidier, J. (1988): Revolution culturelle du temps libre (1968-1988), Paris: Meridiens Klinsieck.

Eco, U. (1986) La estructura ausente. Introducción a la semiótica, Barcelona: Lumen.

Fink, E. (1966): Le jeu comme symbole du monde, Paris: Minuit.

Florida, R. (2002): The Rise of the Creative Class, New York: Basic Books

- (2004): The Flight of the Creative Class. The New Global Competition for Talent, Nueva York: Harper Business, Harper Collins.

- (2009): Las ciudades creativas, Barcelona, Paidós. 
Fumagalli, A. (2010): Bioeconomía y capitalismo cognitivo. Hacia un nuevo paradigma de acumulación, Madrid: Los Libros de la Catarata.

Gardner, H. (2010): Mentes creativas. Una anatomía de la creatividad, Barcelona: Paidós.

Granovetter, M. S. (2000): «La fuerza de los vínculos débiles», Política y Sociedad, no 33, pp. 41-56.

Hardt, M. y Negri, T. (2000): Imperio, Cambridge: Harvard University Press.

Harpur, P. (2007): Realidad daimónica, Girona: Atalanta.

How kins, J. (2005): The Creative Economy. How people make Money from ideas, Londres: Penguin Books.

Houston, D., Findlay, A., Harrison, R. y Mason, C. (2008): “Will attracting the creative class boost economic growth in old industrial regions? A case study of Scotland', Geo-grafiska Annaler: Series B, Human Geography, 90 (2): 133-149.

Howell, J. e Ingham, A. (2001): "From Social Problem to Personal Life Issue: The Language of Lifestyle", Cultural Studies, vol. 15, n 2, pp. 326-351.

Huizinga, J. (1972): Homo ludens, Madrid: Alianza.

Joas, H. (1996): The Creative of Action, Chicago: University of Chicago Press

- (2002): Creatividad, acción y valores. Hacia una sociología de la contingencia, México: Biblioteca de Signos.

Jünger, E. (1993): El trabajador. Dominio y figura, Barcelona: Tusquets.

Koestrer, A. (1975): The act of Creation, London: Picador.

LAfargue, P. (1980): El derecho a la pereza, Madrid: Júcar.

LAHIRE, B. (2004): El hombre plural. Los resortes de la acción, Barcelona: Edicions Bellaterra.

- (2006): La culture des individus. Dissonances culturelles et distinction de soi, Paris: La Découverte.

McCanell, D. (2003): El turismo. Una nueva teoría de la clase ociosa, Barcelona: Melusina.

Nancy, J-L (2000): La comunidad inoperante, Santiago de Chile: Universidad ARCIS.

Noya Miranda, F. J. (1995), «Metodología, contexto y reflexividad. Una perspectiva constructivista y contextualista sobre la relación cualitativo-cuantitativo en la investigación social», en Delgado, J. M. y Gutiérrez, J., Métodos y técnicas cualitativas de investigación en Ciencias sociales, Madrid: Síntesis, pp. 128-145. 
- (2010): “Sociología de la creatividad”, en Noya, J. Del Val, F. y Pérez Colman, M. (comps), Musyca. Música, sociedad y creatividad artística, Madrid: Biblioteca Nueva, pp. 19-40.

Pine, B. J. y Gilmore, J. H. (2000): La economía de la experiencia, Madrid, Granica.

Pohl, Th. (2008): "Distribution Patterns of the Creative Class in Hamburg: Opennes to Diversity as a Driving Force for Socio-Spatial Differentiation?, Erdkunde, vol. 62, nº4, pp. 317-328.

Pujadas Muñoz, Juan José (1992), El método biográfico. El uso de las historias de vida en ciencias sociales, Madrid: CIS (col. Cuadernos metodológicos, $\mathrm{n}^{\circ} 5$ ).

Rodríguez Villasante, T. (2006): Desórdenes creativos. Estilos y estrategias para la transformación social, Madrid: Los libros de la Catarata.

Sarabia, B. (1985), «Historias de vida», Revista Española de Investigaciones Sociológicas, 29. pp. 165-186.

Sennet, R (2009): El artesano, Barcelona: Anagrama.

Sloterdijk, P. (2003): Esferas I, Madrid: Siruela.

- (2012): Has de cambiar tu vida, Valencia: Pre-Textos.

VAN Dijk, T. A. (1998), Ideología. Una aproximación multidisciplinaria, Barcelona: Gedisa.

Verdú, V. (2003): El estilo del mundo, Barcelona: Anagrama.

Weber, M. (1981): La ética protestante y los orígenes del capitalismo, Barcelona: Orbis.

Winnicott, D. W. (1993): Realidad y juego, Barcelona: Gedisa.

Wrigth, O. (1983): Clase, crisis y Estado, Madrid: Siglo XXI. 